\title{
A comparative study of oral, sublingual and vaginal route of misoprostol as cervical ripening agent before surgical method of termination of first-trimester pregnancy
}

\author{
Divya Sinha $^{1 *}$, Sourabh Shrivastava ${ }^{2}$, Swati Shrivastava ${ }^{3}$
}

\author{
${ }^{1}$ Department of Obstetrics and Gynecology, Consultant, ESI hospital Gwalior Madhya Pradesh, India \\ ${ }^{2}$ Gajara Raja Medical College Gwalior, Madhya Pradesh, India \\ ${ }^{3}$ Department of Biochemistry, Gajara Raja Medical College, Gwalior, Madhya Pradesh, India
}

Received: 11 March 2017

Revised: 13 March 2017

Accepted: 18 March 2017

\author{
*Correspondence: \\ Dr. Divya Sinha, \\ E-mail: divyams1708@gmail.com
}

Copyright: (c) the author(s), publisher and licensee Medip Academy. This is an open-access article distributed under the terms of the Creative Commons Attribution Non-Commercial License, which permits unrestricted non-commercial use, distribution, and reproduction in any medium, provided the original work is properly cited.

\begin{abstract}
Background: Cervical ripening is a critical step for surgical method of termination of first trimester of pregnancy. Misoprostol, PGE1 analogue have promising role as cervical ripening agent. The present study aimed to compare the efficacy and side effects of oral, sublingual and vaginal misoprostol at dosage of $400 \mathrm{mcg}$ for cervical priming before surgical method of termination in first-trimester pregnancy.

Methods: It was a prospective hospital based randamosied study. Total 150 patients at 6-12 weeks gestation requesting for medical termination of pregnancy were divided equally in to 3 groups. Every group was advised to have single dose of $400 \mathrm{mcg}$ misoprostol either oral, sublingual or vaginal route respectively 4 hour before suction and evacuation.

Results: The sublingual group had highly significant cervical dilatation $(\mathrm{P}<0.001)$ and the duration of suction and evacuation was less as compared to the vaginal and oral routes $(\mathrm{p}<0.000)$. However, the mean intraoperative blood loss was more in sublingual as compared to the vaginal and oral groups. Loose motions and nausea/vomiting were more with oral routes while blood loss was more in the vaginal route.

Conclusions: Thus, it can be concluded from present study that sublingual route of misoprostol is more preferable than oral or vaginal route as pro-abortion cervical ripening agent.
\end{abstract}

Keywords: Cervical ripening, Medical termination of pregnancy. Misoprostol, Surgical method

\section{INTRODUCTION}

Legally induced abortions, called as medical termination of pregnancy, form a major bulk in every day practice of gynaecology. Medication abortion (also referred to as medical abortion) is the termination of pregnancy with use of medications alone rather than surgery. Mifepristone, $200 \mathrm{mg}$ in combination with misoprostol, $800 \mathrm{mcg}$ is more effective up to 49 days of gestation, rather than in late first trimester of pregnancy. ${ }^{1}$ It is however not always the method of choice because of the long-time consumed to complete the abortion, inconvenience due to prolonged bleeding per vagina $(\mathrm{P} / \mathrm{V})$ and the risk of excessive bleeding $\mathrm{P} / \mathrm{V}$ makes it unsuitable for its use in areas where round the clock emergency services are not available. Therefore, the surgical method like vacuum aspiration, dilatation and evacuation still remains the procedure of choice for termination of pregnancy. Cervical ripening or softening is the determining step for success of surgical method of termination. Insufficiently dilated cervix may cause difficulty in evacuating the uterus, excessive hemorrhage 
and increases the risk of incomplete abortion. Forceful mechanical dilatation may cause cervical laceration and uterine perforation. ${ }^{2}$ Delayed complications of forceful mechanical dilatation like cervical stenosis or cervical incompetence can occur and may be harmful for future pregnancies, especially in nulliparous women. Therefore, medical method of cervical ripening has completely replaced old surgical methods like osmotic dilators or balloon catheter.

Misoprostol, the PGE1 analogue was initially developed as an anti-gastric ulcer drug and approved by FDA for prevention and treatment of gastric ulcer, induced by NSAID (Non-steroidal anti-inflammatory drug) in $1988 .{ }^{3}$ but soon, its uterotonic properties were noted. Uterine effects of misoprostol were not seen in animal studies. Two studies conducted in pregnant ladies in first trimester seeking legal abortions showed that misoprostol was associated with bleeding and complete or partial expulsion of product of conception. ${ }^{4}$

In 1973, first article describing the effect of preoperative cervical dilatation was published. ${ }^{5}$ The first trial using misoprostol as cervical ripening agent has been published in $1994 .{ }^{6}$ Misoprostol is a cheap and effective PGE1 analogue, without many side effects, used worldwide for cervical ripening but has not been sanctioned from patent holders. That is why phase II and III trials usually conducted for optimal dosage, dosage route; timing interval has not been conducted for indications in obstetrics and gynecology.

The study was aimed to compare the efficacy and side effects of oral, sublingual and vaginal misoprostol at dosage of $400 \mathrm{mcg}$ for cervical priming before surgical method of termination in first-trimester pregnancy.

\section{METHODS}

The present study was a prospective hospital based randamosied study, carried out at a tertiary care center following approval from institutional ethical committee over a period of six months ( $1^{\text {st }}$ January 2015 to $31^{\text {st }}$ July 2015). Total 150 patients at 6-12 weeks gestation requesting for medical termination of pregnancy were enrolled for the study after obtaining informed consent and filling the MTP form. Gestation age was confirmed by menstrual history, last menstrual period, bimanual pelvic examination and ultrasonography. Exclusion criteria were contraindication to misoprostol including glaucoma, sickle cell anemia, poorly controlled seizure or known allergy to prostaglandin, history of previous uterine surgery including previous caesarean section, hemoglobin $<8$ gram/dl, known cardio respiratory disease or coagulopathy.

Patients selected for the study were sequentially allocated to three groups of 50 each. Patients selected for the study was told to self-administer $400 \mu \mathrm{g}$ of misoprostol at 6 a.m. at home on the day of scheduled surgery. They were to self-administer the drug by either oral (with little water), sublingual or vaginal route as advised by recruiting investigator on the basis of sequential allocation. Patients were told to report to the hospital at 9 a.m. Suction and evacuation was carried out by the operating surgeon, who was different from the recruiting investigator. The procedure was done on the basis of time of arrival of patients at the hospital and not necessarily in the order of allocation. Therefore, the operating surgeon who was blinded to the route of misoprostol administration could not predict the route of administration during surgery. A detailed history was taken followed by complete physical and pelvic examination of patients. Pre-operative routine investigations including blood group and Rhesus antigens, haemoglobin, random blood sugar, bleeding time, clotting time and urine analysis were done. Preoperatively, side effects associated with misoprostol including pain abdomen, nausea, vomiting, diarrhoea, fever, shivering and bleeding per vaginum were recorded.

Suction evacuation was performed by using Karman's cannula of appropriate size and electric vacuum aspirator under intravenous Diazepam (10mg) and Pentazocin $(30 \mathrm{mg})$. Before starting suction evacuation, the baseline cervical dilatation was measured by Hegar's dilator. The largest Hegar's dilator passing through the internal os without resistance was regarded as the dilation achieved. ${ }^{7}$ If the cervix had a dilation which was appropriate or more for that period of gestation, no further dilation was performed. Additional mechanical dilatation of cervix, if required, was also noted. Intra-operative blood loss was calculated from volume of aspirate in the jar after sieving the product of conception and the operative time recorded as the time from start of cervical dilatation until the end of suction evacuation.

Any cervical or uterine injuries ranging from superficial cervical laceration to an ascending cervical tear, uterine perforation or injury to any other intra-abdominal organs was noted.

Post-operatively, the incidence of nausea, vomiting, diarrhoea, fever, shivering and bleeding per vaginum was noted. As a routine, all patients received analgesics for 2 days and antibiotics for 5 days at discharge from the hospital.

The primary outcome recorded was the baseline cervical dilatation. The secondary outcomes noted were need of additional mechanical cervical dilatation, intraoperative blood loss, operative time and procedure related complications and incidence of side effects of misoprostol.

\section{Statistical analysis}

The data were expressed as Mean \pm SD. One way ANOVA test was applied. $\mathrm{P}<0.05$ was considered as statistically 
significant. Software SPSS 21.0 version was used for analyzing the data.

\section{RESULTS}

Cervical ripening was observed in terms of cervical dilatation before starting suction and evacuation. Table 1 shows that initial cervical dilatation was maximum in sublingual route $(9.3 \pm 5.8 \mathrm{~mm})$ followed by vaginal route $(8.4 \pm 5.2 \mathrm{~mm})$ and least in oral group $(2.6 \pm 4.8 \mathrm{~mm})$. The result has been found to be statistically highly significant with $\mathrm{p}$ value $<0.001$. Thus, additional mechanical dilatation was needed maximum in group of oral route of administration of misoprostol.

The sublingual group (7.0 $\pm 3.6 \mathrm{~min}$.) has taken significantly less time duration for suction and evacuation $(\mathrm{P}=0.000)$ as compared to the vaginal $(8.8 \pm 5.4 \mathrm{~min}$.) and oral $(14.7 \pm 5.1 \mathrm{~min})$ routes (Table 1$)$ However, intraoperative blood loss was more in the sublingual group $(25.8 \pm 18.6 \mathrm{ml})$ as compared to the vaginal $(23.4 \pm 15.7$ $\mathrm{ml})$ and oral $(18.8 \pm 9.5 \mathrm{ml})$ groups (Table 1). Abdominal pain was observed in all the three groups.

Table 1: The effects of misoprostol on different groups.

\begin{tabular}{|llllll|}
\hline Parameter & $\begin{array}{l}\text { Group I oral } \\
\text { route } n=50\end{array}$ & $\begin{array}{l}\text { Group II Sublingual } \\
\text { route } n=50\end{array}$ & $\begin{array}{l}\text { Group III } \\
\text { Vaginal route n=50 }\end{array}$ & $\begin{array}{l}\text { F } \\
\text { value }\end{array}$ & P value \\
\hline Initial cervical dilatation $(\mathrm{mm})$ & $2.6 \pm 4.8$ & $9.3 \pm 5.8$ & $8.4 \pm 5.2$ & 23.7 & $0.000^{* *}$ \\
\hline Duration of procedure $(\mathrm{min})$ & $14.7 \pm 5.1$ & $7.0 \pm 3.6$ & $8.8 \pm 5.4$ & 35.7 & $0.000^{* *}$ \\
\hline Intraoperative blood loss $(\mathrm{ml})$ & $18.8 \pm 9.5$ & $25.8 \pm 18.6$ & $23.4 \pm 15.7$ & 2.8 & $0.065^{\mathrm{NS}}$ \\
\hline$* *$ Highly significant at $\mathrm{p}<0.001, \mathrm{NS}$ Non-significant. & & & &
\end{tabular}

Table 2 shows that patients who have taken sublingual misoprostol experienced bitter taste, nausea due to local effects while other gastrointestinal side effects like vomiting, diarrhoea were negligible in sublingual and vaginal routes as both bypass first pass metabolism in liver.

We found that post-operative vaginal bleeding was more in the vaginal group and 2 patients in oral group developed pyrexia (Table 2).

Table 2: The post-operative side effects in all three groups.

\begin{tabular}{|lll|l|}
\hline $\begin{array}{l}\text { Side } \\
\text { effects }\end{array}$ & $\begin{array}{l}\text { Group I } \\
\text { oral route } \\
(\mathbf{n}=50)\end{array}$ & $\begin{array}{l}\text { Group II } \\
\text { sublingual } \\
\text { route }(\mathbf{n}=50)\end{array}$ & $\begin{array}{l}\text { Group III } \\
\text { Vaginal } \\
\text { route }(\mathbf{n}=50)\end{array}$ \\
\hline Vomiting & 2 & 0 & 0 \\
\hline Nausea & 6 & 2 & 0 \\
\hline $\begin{array}{l}\text { Vaginal } \\
\text { bleeding }\end{array}$ & WNL & WNL & WNL \\
\hline Fever & 2 & 6 & 0 \\
\hline Dizziness & 1 & 1 & 0 \\
\hline Diarrhoea & 1 & 0 & 0 \\
\hline
\end{tabular}

WNL: Within normal limit

\section{DISCUSSION}

Several studies have assessed the efficacy of prostaglandins with or without mifeprstone. ${ }^{8}$ Misoprostol is prostaglandin of choice as it is cheap and stable at room temperature and available in different dosage forms. ${ }^{9}$ Misoprostol binds to myometrial cells causing strong myometrial contractions leading to softening and dilatation of cervix. This results in separation of conceptus from uterus thereby initiating abortion process before suction and evacuation. Thus, results in case of cervical dilation, reduced procedure time and less intraoperative blood loss. Due to lack of evidence from large randomized studies consensus has not been drawn regarding optimal dose, time interval and route of administration of misoprostol as preabortion cervical ripening agent.

The present study observed that initial cervical dilatation by misoprostol were favorable with sublingual group followed by vaginal group, therefore operative time was found to be shortest in the sublingual group. The results were comparable with the study by Saxena et al and Tang et al. ${ }^{10,11}$

Tang et al, as compared the absorbtion kinetics and systemic bioavailability of misoprostol by oral, sublingual and vaginal route and vaginal route with addition of water. $^{12}$ They found that sublingual misoprostol achieved significantly higher peak serum concentrations $\quad(574.8 \pm 250.7 \mathrm{pg} / \mathrm{ml})$ than oral $(287.7 \pm 144.3 \mathrm{pg} / \mathrm{ml} ; \mathrm{p}<0.001)$ or vaginal $(125.2 \pm 53.8 \mathrm{pg} / \mathrm{ml})$ routes. The time to peak was similar in both the sublingual $(26.0 \pm 11.5 \mathrm{~min})$ and oral groups $(27.5 \pm 14.8 \mathrm{~min})$ and was significantly shorter than that in both vaginal groups. The area under the misoprostol acid concentration versus time curve up to 360 min was also significantly higher with the sublingual route $(743.7 \pm 291.2 \mathrm{pg} / \mathrm{h} / \mathrm{ml})$ compared with the oral $(402.8 \pm 151.6 \mathrm{pg} / \mathrm{h} / \mathrm{ml} ; \quad P=0.05) \quad$ and vaginal $(433.7 \pm 182.6 \mathrm{pg} / \mathrm{h} / \mathrm{ml})$ routes.

The mean intra-operative blood loss was less in the oral group, albeit it was higher than reported by Saxena et al. ${ }^{10}$ The total duration of surgery was less in the 
sublingual group that can be explained on the basis of more cervical ripening and dilatation achieved in this group. These results were however different from those obtained by Saxena et al. ${ }^{10,13}$

The observed side effects like abdominal pain, loose motions, vaginal bleeding, nausea and vomiting were quite different from the earlier studies by Tang et al where the incidence was high which may be because of the higher and the frequent dosing used in the first study.9,14 Vaginal bleeding in our study was less in the vaginal group than the other two groups, which could be attributed to the sustained peak plasma concentration in this route.

\section{CONCLUSION}

We observed in the present study that Sublingual misoprostol causes adequate cervical dilatation and facilitate surgical abortion by reducing blood loss, operative time and complication rate significantly. Though it may cause bitter taste, nausea and vomiting, incidence is much less than that in oral route because buccal mucosa is very vascular and misoprostol tablet being soluble in water dissolves within 10-15 minute of administration, bypasses first pass metabolism in the liver. ${ }^{11}$ Vaginal misoprostol is also found to be an effective route due to its slow and more constant absorption through the vaginal mucosa and negligible gastrointestinal side effects. As remnants of tablets may be found many hours after vaginal administration and discomfort associated with its administration through vaginal route limits its universal acceptance in clinical practice among patients.

Thus, from the present study it can be concluded that sublingual is more preferable and well tolerated than oral or vaginal route of administration of misoprostol, as cervical ripening agent for surgical method of medical termination of pregnancy.

Funding: No funding sources

Conflict of interest: None declared

Ethical approval: The study was approved by the Institutional Ethics Committee

\section{REFERENCES}

1. Creinin MD. Medical management of abortion. American Journal of Obstetrics and Gynecology Practice Bulletin. 2001;26:1-13.

2. Molin A. Risk of damage to the cervix by dilatation for first trimester- induced abortion by suction aspiration. Gynecol Obstet Invest. 1993;35(3):152-4.

3. Graham DY, Agrawal NM, Roth SH. Prevention of NSAID-induced gastric ulcer with misoprostol: multicentre, double-blind, placebo-controlled trial. Lancet. 1988;332:1277-80.

4. Herting RL, Nissen $\mathrm{CH}$. Overview of misoprostol clinical experience. Dig Dis Sci 1986;31:47S-54S.

5. Toppozada M, Bygdeman M, Papageorgiou C, Wiqvist N. Administration of 15- methylprostaglandin-F2_ as a preoperative means of cervical dilatation. Prostaglandins. 1973;4:371-79.

6. El-Refaey H, Calder L, Wheatley DN, Templeton A. Cervical priming with prostaglandin E1 analogues, misoprostol and gemeprost. Lancet. 1994;343:120709.

7. Singh K, Fong YF, Prasad RN and Dong F. Randomised trial to determine optimal dose of vaginal misoprostol for preabortion cervical priming. Obstet Gynecol. 1998;92:795-98.

8. McKinley C, Thong KJ, Baird DT. The effect of dose of mifepristone and gestation on the efficacy of medical abortion with mifepristone and misoprostol. Hum Reprod. 1993;8:1502-5.

9. Tang OS, Miao BY, Lee SW, Ho PC. Pilot study on the use of repeated doses of sublingual misoprostol in termination of pregnancy up to 12 weeks gestation: Efficacy and acceptability. Hum Reprod. 2002;17:654-8.

10. Saxena P, Sarda N, Salhan S, Nandan D. A randomised comparison between sublingual, oral and vaginal route of misoprostol for pre-abortion cervical ripening in first-trimester pregnancy termination under local anaesthesia. Aust N Z J Obstet Gynaecol. 2008;48:101-6.

11. Tang OS, Mok KH, Ho PC. A randomized study comparing the use of sublingual to vaginal misoprostol for pre-operative cervical priming prior to surgical termination of pregnancy in the first trimester. Hum Reprod. 2004;19:1101-4.

12. Tang OS, Miao BY, Lee SW and Ho PC Pharmacokinetics of different routes of administration of misoprostol. Hum Reprod. 2002; 17:332-36.

13. Saxena P, Salhan S, Sarda N. Comparison between the sublingual and oral route of misoprostol for preabortion cervical priming in first trimester abortions. Hum Reprod. 2004; 19:77-80.

14. Tang OS, Lau WN, Ng EH, Lee SW, Ho PC. A prospective randomized study to compare the use of repeated doses of vaginal with sublingual misoprostol in the management of first trimester silent miscarriages. Hum Reprod. 2003;18:176-81.

Cite this article as: Sinha $\mathrm{D}$, Shrivastava $\mathrm{S}$, Shrivastava S. A comparative study of oral, sublingual and vaginal route of misoprostol as cervical ripening agent before surgical method of termination of first-trimester pregnancy. Int J Reprod Contracept Obstet Gynecol 2017;6:1295-8. 